\title{
ETHICS IN THEORY AND PRACTICE IN SPANISH HEALTHCARE COMMUNITY INTERPRETING
}

\author{
Carmen Pena-Díaz \\ carmen.pena@uah.es \\ Universidad de Alcalá
}

\begin{abstract}
Community interpreters carry out their daily work within different contextual situations and follow specific codes of ethics, whilst at the same time they are confronted with communicative conflicts in which ethical responsibilities may overlap with their professional duties. The aim of this article is to understand the significance of ethical issues in Spanish healthcare interpreting and to determine to what extent 'unethical' interpreting (according to codes of ethics) can become a barrier or a bridge to effective communication. The article explores the challenges, conflicts and dilemmas encountered by public service interpreters in healthcare in Madrid, and examines the beliefs held by these professionals regarding their knowledge of codes of ethics, as well as their implementation. The findings show that the participants' perceptions of their beliefs and knowledge of codes of ethics were not as impartial as they thought, as they assumed functions which codes of ethics do not consider appropriate.
\end{abstract}

\section{Resumen}

Los intérpretes de servicios públicos desarrollan su profesión en distintas situaciones contextuales, siguiendo códigos éticos específicos, al mismo tiempo que se enfrentan a conflictos y dilemas comunicativos en los que las responsabilidades éticas pueden superponerse a sus tareas profesionales. El objetivo de este artículo es comprender la importancia de las cuestiones éticas en la interpretación sanitaria española y determinar hasta qué punto la interpretación 'no ética' puede convertirse en una barrera o un puente para hacer la comunicación efectiva. Exploramos los desafíos, conflictos y dilemas de un grupo de traductores e intérpretes de servicios públicos en el ámbito sanitario en Madrid y examinamos las creencias de estos profesionales en cuanto a su conocimiento de los códigos de ética y su implementación, para mostrar que las 
percepciones de los participantes sobre los códigos éticos no eran tan imparciales como creían, al asumir funciones que los códigos de ética no consideran apropiadas.

Keywords: Community interpreting. Public service interpreting. Healthcare. Ethics

Palabras clave: Traducción e interpretación en los servicios públicos. Sanitario. Códigos éticos. 


\section{Introduction}

Interpreting is the task of facilitating communication as accurately as possible between two parties who do not share a common language; it is much more than merely transferring linguistic utterances from one language to another, and the fact of knowing two languages does not make a translator or interpreter any more than having two hands makes a pianist. Whilst it is "one of the oldest of human activities" (Gentile, Ozolins \& Vasilakakos 1996: 5), it remains a profession which has been seeking recognition for decades. Northern European countries, together with Canada and Australia have acquired and managed to develop a certain degree of social awareness for the need of these professionals within community services; however, Mediterranean countries have still not attained this level of professionalism.

In Spain there are no official qualifications required to become a professional interpreter (i.e. there is no need to hold a specific degree in order to practise this profession), and although there are many university programmes which train future interpreters, it is incorrectly presumed by lay people that any bilingual individual can fulfil this role. This is regardless of the fact that a qualified professional should undertake the duties and tasks required of each specific context and setting (Pena et al. 2014). Recognition of the profession by the general public would demonstrate that these professionals not only need to be knowledgeable about proceedings, protocols, tasks and duties, but that they are also aware of the principles and rules which guide professional and ethical obligations, especially during sensitive interactions, where special attention should be given to issues of confidentiality. In healthcare contexts, users need to know that when interpreters engage in their interaction then they will comply with professional values and standards, and professionalisation and ethics play a major role in this regard.

After decades of steadily increasing numbers of incoming migrants to Spain, Spanish society has changed over the past two decades and there is now a coexistence between citizens and people from other countries, thus notions such as interculturalism, defined as a new expression within cultural pluralism (Giménez 2010), have taken on an important and crucial role. The 
importance and need for research in this area is vital in the public service sector in order to study the management of this diversity and to enable appropriate intercultural communication.

Despite not receiving the institutional support they deserve, educational institutions are contributing towards professionalisation in all areas concerning interculturalism. A growing volume of training proposals such as Master's degrees, practical initiatives, and research projects have been incorporated into studies on language and cultural communication. Many efforts have been made to further enrich the growing literature in this area from different perspectives. Exhaustive articles encompassing past studies such as that published by Sales and Valero (2006) have appeared, thus providing a categorised tool that is very useful for both students and researchers. As a continuation of the study, Pena et al. (2014) also analysed the literature from 2005 until 2011, although they focused on the study of intercultural mediation in healthcare, a more generic term including translation and interpretation, to bring together some of the most important research studies on this topic. Other authors, such as Franco Aixelá (2010), have presented a quantitative analysis of compilations such as BITRA (Bibliography of Interpreting and Translation ${ }^{1}$ ), focusing on related medical translation and interpretation publications. Recent work by another research group, the CRIT (2014), has been dedicated to different issues, such as ethics and practice in healthcare interpreting. Studies have also been undertaken relating to specific regions, such as an article by Vargas-Urpi (2014) where the author described the professionalisation of public service interpreters in Catalonia.

The aim of this paper is to conduct a study based on a group of public service interpreters and translators (PSIT, the academic term used in Spain) in Spain in order to determine their theoretical views on different codes of ethics and to then establish whether this knowledge is put into practice in their everyday work in healthcare contexts. Participants were issued with a survey which contained questions concerning ethical issues and were later observed in their daily work. The ultimate goal of this research is to further study how theory and practice coexist in a specific intercultural setting and the role given to ethics in such a context.

1. Available at www.ua.es/dpto/trad.int/base/ index.html 


\section{Defining Community Interpreting in Spain}

It is essential to define what is understood by community interpreting $(\mathrm{CI})$, as its definition is key to understanding the different approaches to ethics. Many attempts have been made to define what is referred to as public service interpreting (PSI) or $\mathrm{CI}^{2}$ in English speaking countries; however, in Spain the issue of differentiating between both terms remains a recurring one (Antonin 2010; García-Beyaert \& Serrano-Pons 2009; Llevot 2005; Navaza, Estevez \& Serrano 2009; Ponce Márquez 2011; Raga 2008; Navaza 2011). As stated by Antonin (2010: 132), "the main reason for this apparent difference is a widespread uncertainty affecting them, which (...) has led interpreters and mediators to cry for a long time for a conceptual and professional recognition that does not end there."

Interpreting in its wider definition is now considered a profession, although it is still only fully recognised in specific institutions, such as the Spanish Foreign Department (Ministerio de Asuntos Exteriores), the Diplomatic Service, etc. and it is not well defined. Spain is a country where interpreting per se is strictly seen as conference interpreting. Community Interpreting (CI) is less developed as a profession than many other forms of interpreting, and more work needs to be undertaken in this area. This could be due to the beginnings of CI, when Gentile in 1997 used an array of terms to demonstrate how difficult it is to arrive at a definitive description, and he argued that $\mathrm{CI}$ is simply interpreting. Years later, we are still trying to reach definite conclusions about the term. In very recent work, Ozolins (2014) argues that the different descriptions given to interpreting outside the conference room have bedevilled the field, from 'community interpreting' to 'dialogue interpreting', 'public service interpreting', 'ad hoc interpreting' and 'non-professional interpreting'. Some descriptions avoid the term 'interpreting' altogether, such as 'linguistic mediation', 'cultural mediation' etc. Significantly, self-ascription by practitioners themselves often does not match these imposed descriptions. However, each description carries with it, either implicitly or explicitly, a specific view of ethics, which is closely tied to the perceived roles of interpreters and yet, often encompasses assumptions about tasks, personal or professional characteristics, or status.

The use of the term 'intercultural mediator' in Spanish coincides and overlaps to a large extent with the English terms 'public service interpreter' and 'community interpreter'; however, the historical role of this professional

2. The term 'intercultural/interlinguistic mediator' is frequently used in Spanish (Sales 2006). 
in Spain is quite different from that in Anglo-Saxon countries, and thus the interpreter's role varies. In recent work by Baixauli (2014), the English terms PSI and CI and their definitions are used to define the Spanish term which accommodates both: mediación interlingüistica e intercultural en el ámbito sanitario (MILICS), which he equates to the most frequently used term, traducción e interpretación en los servicios públicos (TISP). We agree with Baixauli's argument, which goes back to the statements by Katan (2011) and Pöchhacker (2008), that all interpreters are (linguistic and cultural) mediators but not all mediators are interpreters. The term CI will be used throughout this paper.

In earlier work, Ozolins (2000) classified the different stages that countries undergo in the role of CI. Taking this into account, Spain can be classified somewhere in the mid stages, as it is still using ad hoc services and generic language solutions, and therefore remains in the professionalisation stage. However, from a positive perspective, it can be established that Spain may be close to reaching Ozolins' comprehensive stage, where training, accreditation and specialisation of interpreters, both regarding context and languages, is beginning to take place. In fact, the national agency for assessing quality in higher education in Spain, ANECA, referred to the linguistic and cultural mediator' as a professional, together with the general translator, reviewer, etc. when they published the Translation and Interpretation Studies White Book draft in 2004 (ANECA 2004). The fact that the profession is mentioned means that it is recognised as such by educational authorities, which is a significant step to raise awareness; although further work and awareness are of course still needed.

According to García Beyaert and Serrano Pons (2009: 57), the interpreters (legal, for example), who may work in public services, have a less interventionist role and their work is focused on enabling communication between parties by overcoming existing barriers via their linguistic and cultural knowledge. In contrast, the role of a CI is intended to both reduce differences between two remote parties for reasons of identity, culture, ethnicity, and to 'build bridges between immigrants and the institutions of the host society' (García Beyaert \& Serrano Pons 2009: 56). In other words, interpretation can be considered an aspect of CI or intercultural mediation (Sales 2005, cited in Ponce Márquez 2011: 233).

The functions performed by $\mathrm{CI}$ are multifaceted within the Spanish public service health context. The facilitation of communication between healthcare personnel and immigrant and ethnic minority patients is the main task carried out by these professionals, although they are also asked to translate health information leaflets and other documents, thus the term 'public service 
interpreter and translator' (PSIT) has been instigated. In addition, CI working in healthcare settings may be required to inform patients about procedures and the organisation of the Spanish health system, which implies that they should possess a thorough knowledge of hospital administration and health services in the host country, as well as in a patient's home country. However, institutions and associations involved in public health services have not yet assumed the broad knowledge required to carry out CI effectively. Navaza, Estévez \& Serrano (2009) highlighted that it is still wrongly believed that translation/interpretation is only linked to words and not to the ideas behind them and therefore the absolutely essential cultural component is lacking. In particular, the above mentioned authors have shown their concern for the great importance that non-governmental organisations (NGOs), immigrant associations, and political and health institutions, attach to intercultural mediators' command of languages to the detriment of the knowledge these professionals should have regarding the specialised vocabulary and specific techniques required during translation and interpretation (2009: 152).

Given the situation described above, we believe that corrective actions should be taken in order to raise awareness of the complexity of the community interpreter's profile. Informative sessions could be held to explain to these associations and institutions that the effectiveness of communication in patient-doctor meeting requires a wide range of skills that go beyond a mere command of languages, and that ethical aspects are crucial in this type of interactions during which personal and sensitive information is shared. Navaza (2014), among others, in fact, describes this as one of the Cl's main roles at present.

\section{Ethics in Community Interpreting}

As Trabing (2007: 1) states, CI require "much personal interaction with the client" and also "knowledge of the client's cultural background"; therefore, these professionals need to act as a cultural bridge between health providers and clients (patients). The $\mathrm{CI}$ is thus a professional who has to deal with his or her personal baggage (language, culture, ideology, etc.), their client's personal baggage, the health professional's personal baggage and the service provider's criteria. This section deals with the ethics involved in the interpersonal triadic relationship between interpreter, user and health practitioner in general, in order to explain the issues we consider to be fundamental.

Navaza (2014: 10) states that language and culture are intrinsically linked and it is necessary to make out the referential meanings of the verbal and non-verbal language of the participants in order to transfer messages to another 
language. Having reviewed the various ethical codes available such as the IMIA (International Medical Interpreters Association) or the NCIHC (National Council on Interpreting in Health Care), among others, and taking into account that there is no specific healthcare interpreting code of ethics in Spain, much is left to an interpreter's 'common sense', which is quite a subjective concept. Thus, the Standards for the Practice of Medical Interpretation (IMIA) include the term 'cultural interface' referring to the need for the interpreter to share cultural information which may be considered relevant and could help mitigate misunderstandings and clarify communication. This leaves grounds for the interpreter to omit or add information as far as s/he considers necessary, which gives way to personal subjectivity.

Due to the interactional nature of $\mathrm{CI}$, these professionals often find themselves confronted with ethical dilemmas in situ for which they need to refer to a specific code of ethics in order to guide and protect themselves in their everyday practice. As Dragoje \& Ellam (2012) state, the good use of their ethical code will help interpreters to handle the many challenges and dilemmas that arise during an interpreting event. Accordingly, adherence to professional ethics should be classified as one of the main issues in each assignment that a practitioner undertakes. The issue of ethics is thus very important, especially due to the degree of trust that is placed on interpreters and their responsibility in delicate and intimate personal areas, such as health. This is the main reason for the importance of uniform ethical standards that guide and protect interpreters in their duties. The code of ethics is thus a management tool that establishes and articulates the responsibilities, values, obligations, rights and ethical ambitions of professionals, and also the way the system functions. As stated by Solow (1980: 39), "a code of ethics protects the interpreter and lessens the arbitrariness of his or her decisions by providing guidelines and standards to follow'. However, as will be seen through specific examples presented later in this paper, there are certain concepts that are difficult to maintain at an impartial level when dealing with interpersonal relations, and these become more and more complex as cultural and ideological differences arise. As stated by Gentile et al. (1996: 57):

Liaison interpreting is a profession where, like medicine, teaching and the law, the client's welfare is usually affected directly. This is not only because most liaison interpreting takes place in the context of other professions such as medicine, teaching and the law, but also because interpreting has its own knowledge, skills and practices which require particular ethical situations.

Training in ethical issues should occupy a major role in courses dedicated to CI training. As can be seen from a report published by Routes into Language 
(2012) on training provision for public service interpreting and translation in the UK, ethics is a key aspect which should be taught and assessed during training programmes. Not only in the UK but elsewhere, there has been increased interest in the ethical issues associated with public service interpreting and translation. Research in this area has been conducted by many authors, including Valero \& Martin (2008), Corsellis (2005) and Rudvin (2007). However, it is an area which is difficult to integrate in a practical way during formal training. Ethical codes may be presented and even analysed in the classroom, but the wide range of situations where ethical problems may arise during everyday work cannot be covered in general CI training programmes. Students can carry out role plays and be given examples of different situations, however, there will be many contexts which have not been analysed in the classroom. Thus students are left with mostly theoretical guidelines which are sometimes very difficult to put into practice. Although a code of ethics provides guidance on how to handle conflicts and situations, it may pose dilemmas between different actions or pressures, and does not guarantee on its own the perfect selection between right and wrong choices, as it is only effective and useful "with committed dissemination, implementation, monitoring and embedding at all levels so that behaviour is influenced" (Dragoje \& Ellam 2012: 1).

There is little that can be done as far as personal and interpersonal perceptions and understanding of ethical issues are concerned, but it was also found that codes of ethics, even when intended for $\mathrm{CI}$, whilst they may present very useful parameters for general interpreters, do not cater for CIs specifically.

In theory, it is reasonable to expect that a code of conduct may be a functional tool which can be applied and consulted in a practical and realistic way in most settings. However, for CIs it is not reasonable to expect that this will be applicable in the same way, as they face more cultural and ideological nuances in more interventionist and less formal settings than for example conference interpreters, and thus many more different and unique situations may arise. It is quite frequent for CIs to be faced with situations where torture, asylum, violence and many other emotionally charged events are part of the interaction, making it difficult for formal, emotionally uninvolved linguistic transmission.

Ethical implications for different types of public service interpreting are not equivalent; professionals working in court interpreting regard accuracy and impartiality as their main priority, whereas the main ethical concern for interpreters in health contexts is their duty of care to the patients. This has been noted by Ozolins (2014), who highlighted the gaps which inevitably exist between codes and practice. Although the same concerns exist for those who do not speak the majority language in institutions in all settings, CIs 
working in health contexts often need to advocate for patients and to clarify cultural concepts and issues, as minorities need to understand institutional practices and institutions need to understand the cultural needs and differences of minorities that may affect their healthcare, thus sometimes they have to act as cultural clarifiers. In everyday work, CIs in healthcare settings engage in patient advocacy, as noted by Angelelli (2004).

Consequently, ethics plays a core position in $\mathrm{CI}$ and should be a major concern during training. Future research in the Spanish context should be dedicated to establishing the main lines of action regarding methodology in this area. As Vargas-Urpi (2012: 67) states "training tries to prepare interpreters-to-be for real life work and, thus, is dependent on research that reflects real life - ethics, contexts, working conditions, history'.

Many authors, such as Hale (1997a, 1997b), Mikkelson (1996b, 1998) and Wadensjö (2011) have debated whether the CI should be neutral. Wadensjö (1998: 287) stated that this type of interpreter should be faithful to the people $\mathrm{s} /$ he interprets rather than to the text, depending on the situation and context and their needs, combining two different roles in order to guarantee communication between user and provider: "relaying others' talk" (transmitting the message) and "co-ordinating others' talk" (balancing participant intervention so that the exchange is relevant). Two different models can be said to exist and authors such as Mason (1999) and Cambridge (2003) have dealt with this issue. Cambridge (2003: 110-123) delimits both models, differentiating one which is patient biased and warns that in this case the interpreter should make sure s/he does not omit information or adds insignificant elements, lose impartiality or take on tasks which do not belong to the interpreter, from an 'impartial' model in which the interpreter transmits every single utterance and can only clarify aspects which s/he is asked to clarify (Cambridge 2002: 115).

Ongoing issues in translation and interpreting studies, such as interpreters' (in)visibility and their role, are central when discussing ethics and are of major importance for future CIs. Arguments range from the perspective of Cambridge (2002: 123) concerning the importance of a Cl's impartial model, in which they should:

(...) relay messages accurately, completely and in as closely as possible the same style as the original. They do not give personal advice or opinions; do not add or omit parts of the message; do make every effort to foster the full, accurate transfer of information; do maintain strict confidentiality. They will intervene only when they need clarification of part of a message; they cannot hear what is being said; they believe a cultural inference has been missed; they believe there is a misunderstanding. 
to Pöllabauer (2004) who states that traditional codes of ethics may only be valid on paper, and Rudvin (2007) who proposes that interpreters should possess more competences to adapt to each institution's needs as opposed to holding one universal deontological code, as this may not foresee the great variety of interpretative situations caused by ideological and cultural factors. As Rudvin (2007: 52) states:

Community interpreting as a profession is still very heterogeneous; the interpreter's role is often defined by how the institution uses him/her and what its needs are. Consequently, establishing a universal or near-universal code of professional ethics becomes highly problematic; it also impacts on crucial issues such as impartiality. The paper argues that the complex nature of professionalism and of cross-cultural differences in attitude towards professional role and social identity will have to be addressed by the professional community to improve quality and working conditions for clients, users and interpreters.

Again, this relates to the type of work and contexts which these professionals may encounter. For example, a conference interpreter or a CI working in a legal setting has a less interventionist role and their work is focused on enabling communication between the parties by breaking down existing linguistic barriers, whereas a $\mathrm{CI}$ in healthcare also has to take into account elements such as identity, culture, and ethnicity, and cannot limit their practice to simply linguistic and cultural differences, but must also consider intervening in ethnic and ideological issues, which are concrete and specific to each individual and his or her background and personal experience.

As Tate \& Turner (2001: 53) state, "what no code can do is anticipate all possible situations". The concepts which tend to appear in all codes of ethics are confidentiality, professional conduct, interpreter rights, solidarity among professionals, and impartiality. The last point implies some degree of subjective interpretation, which the individual interpreter must deal with for each particular context. In particular, when we come to cultural bridging, how far can a CI go in order to establish whether an explanation is necessary for an accurate understanding by all the different parties involved? If the words of a healthcare professional are interpreted in isolation, without reference to their use in the context in which they are said, then in many cases a patient will not be able to fully understand the message and thus communication will not be established.

\section{Study Structure and Methodology}

The main aim of this study was to research ethical issues through a group of interpreters, in order to obtain a better understanding of the realistic or 
unrealistic expectations placed on them. The first stage of the study consisted of questionnaires, relating to issues that concerned ethics and the respondents' general knowledge about codes of ethics. The questionnaires were used to extract data pertaining to knowledge related to interpreters' codes of ethics. In the second stage of the study, participants who had answered the questionnaire were contacted and observations of 13 of these interpreters for two 20 minute sessions in healthcare centres in Madrid were undertaken.

\subsection{Participants}

A questionnaire was designed and used as the instrument to measure the results for this study. Participants included professionals working in Madrid as interpreters, both in-house and freelance, as well as postgraduate students who had professional experience. Questionnaires were sent out via email on a general scale to translation and interpreting professional associations without taking social factors or age into account in order to receive as much feedback as possible. A general introduction briefly outlining the research rationale and a participant acceptance consent form were sent with the questionnaire (Appendix 1) to 40 participants during the initial stage and this was extended through social networks to widen the sample during the second stage.

\subsection{Stage 1: Questionnaire}

The questionnaire consisted of ten questions, with the first six devoted to personal information, such as gender, professional status, working languages, and type and length of work. The final four questions were specifically designed to acquire information concerning ethical issues, such as whether they followed a particular code or if they had received specific training with regards to ethics, as well as whether they considered ethics to be important in their profession. The purpose of including such a limited number of questions was to guarantee that the questionnaires were completed and returned.

The response rate was smaller than expected during the first stage, with a response rate of $22.5 \%$ (40 questionnaires were sent and only 9 returned); however, by extending the distribution through social networks, 22 additional questionnaires were collected, therefore obtaining a total of 31 completed questionnaires.

Aside from postgraduate students who had worked as interpreters but not in public services and thus could not be included in the sample, feedback was obtained from 31 experienced CIs. The main reason for such a small sample is probably due to the fact that the Madrid regional government, under the pretext 
of the global economic crisis, has reduced this social service and the only available option practitioners now have is a telephone service that can be used when they consider that there is no effective communication with patients.

\subsection{Stage 2: Observation}

Out of the 31 qualifying participants, 27 agreed to participate in the second stage of the study. These participants were all CIs with more than two years of experience in healthcare settings. Two 20 minute sessions, during which both the practitioner and patient gave permission for us to be present at the interaction, were observed. We were not permitted to record or take notes so as not to damage patient privacy. All observations took place at healthcare centres in Madrid, with 19 interpretations between Chinese and Spanish, and eight between English and Spanish.

\section{Results and discussion}

Earlier in this paper it was suggested that interpreters have to analyse the meaning of a message in order to then translate it as accurately as possible by choosing the right words, with the objective of a clear interaction whereby participants understand and communicate effectively with each other. CIs carry out their work in situations which are usually emotionally charged and sensitive (healthcare, courts, etc.) and, thus, include in their interactions much more than words; verbal and non verbal language comes into play, as well as ethical and ideological issues, which may be fundamental in order to achieve effective and complete communication. In this study the objective was to determine whether the CIs understood the importance of ethics and which ethical issues they faced in their daily work.

\subsection{Analysis of the results of the questionnaire}

As we can see in Table 1, the responses suggested that the majority (81\%) of the participants were knowledgeable concerning codes of ethics and actually used a specific code, that of the Spanish Professional Association of Translators and Interpreters (ASETI, Asociación Profesional Española de Traductores e Intérpretes) and also the National Council on Interpreting in Health Care. There is no specific code for Spanish healthcare CIs. 


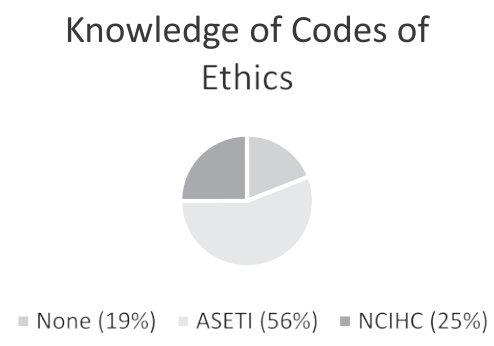

Table 1: Knowledge of Codes of Ethics

However, as we can see in Table 2, 47\% stated that their code of ethics related to common sense and did not mention any specific code. One interpreter actually mistook ethics with work protocols. Aside from this one interpreter, the remaining interpreters all mentioned confidentiality, impartiality and non-discrimination, which are the main elements included in codes of ethics.

\section{Use of specific Code of Ethics}

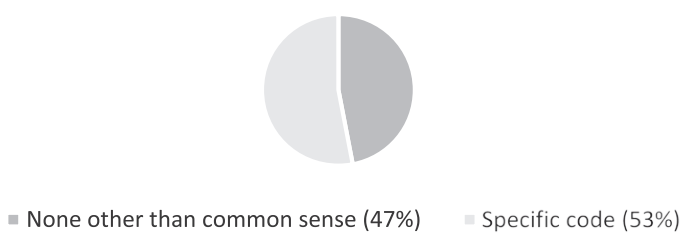

Table 2: Use of a specific Code of Ethics

The type of ethical issues that they raised included the difficulty of becoming involved in interpretations not related to health, for example when users ask interpreters to help them with interpretations outside their work place; not agreeing with a practitioner or patient's comments; deciding whether to adhere to interpretation as such or to mediate; what to do when asked to lie or condone; what to do when a client asks for information which is not strictly given but the interpreter may have access to; and when asked not to interpret part of the discourse.

In all cases, when posed with dilemmas such as those mentioned above, the respondents stated that they followed the guidelines of a code of ethics, establishing and articulating the values, obligations, responsibilities and ethical issues of the health centre where they were. They also stated that they had all received specific training on ethical issues in their past studies and considered 
this to be an essential part of their training, as well as for their daily professional activities.

A recurring comment was that they would find it very helpful to attend a presentation or be issued with initial protocols where basic neutrality, confidentiality and faithfulness principles and guidelines were outlined, as well as basic instructions for the exchange that would be occurring. This information would help interpreters if ethical conflicts were to arise, as well as for communication purposes.

To summarise, most interpreters (81\%) were knowledgeable of specific codes of ethics based on confidentiality, impartiality and non-discrimination. In particular, they tend to follow the code of ethics of the Spanish Professional Association of Translators and Interpreters ASETI (Asociación Profesional Española de Traductores e Intérpretes), the code of ethics imposed by the commission (if given), or the National Council on Interpreting in Health Care's code. This reveals that interpreters use local and specific guidelines rather than general, international ones, which proves the need to create a specific Code of Ethics for heath CIs in Spain.

\subsection{Analysis of the observation process}

Having analysed the questionnaires, we then wanted to see these professionals in their everyday work and to assess whether the information they had supplied corresponded to their practice. With reference to their questionnaire answers, we were particularly interested in their answers to the last two questions: whether they had received specific training related to ethics and whether they considered it to be a highly important part of their training. The observer paid special attention to situations which could entail ethical problems for the interpreters with reference to Question 7: "Do you have to face ethical decisions on a daily basis as an interlinguistic and intercultural mediator?" and Question 8: "As part of your job, do you follow any specific ethic code?".

All participants answered that they encountered daily ethical dilemmas in their work and this was proved during the observations. Ethical issues that could be classified as difficult included some of those noted in the questionnaire responses. During the observations the interpreter had to facilitate additional information concerning different issues, including the Spanish vaccination schedule, how to make further appointments, where to find information about health services, why the practitioner was requesting blood tests and why this was necessary, and why the doctor was prescribing a certain medicine. In all cases, the different interpreters involved did not hesitate to facilitate this information. In two cases, the interpreters were asked by the patients to lie about a 
previous appointment, with the patient asking the interpreter to say that he had been there at the appointment time. One of the interpreters omitted this from her interpretation, whereas the other interpreter transmitted this information. All the respondents stated that when they were posed with an ethical dilemma they followed the guidelines of a code of ethics; however, the issue of facilitating further information is not recommended and there are no protocols for omitting information whilst interpreting. This reveals that CIs do not always follow ethical guidelines, as much as they believe they do.

The non-Spanish speaking community requesting the services of the interpreters were mostly Chinese, followed by Africans, mostly of Nigerian origin. Most people who come to Spain do not have enough information about the Spanish health system or diseases that may occur and how to treat them or how to avoid getting them, especially in the case of sexually transmitted diseases. These problems are added to the fear of going to the doctor when in an irregular situation, due to the lack of a health card or fear of being arrested by the police and deported. In addition to these factors, the immigrants' own culture and traditional practices also affect the way in which they perceive and use medicine. Traditional medicine and the practice of all kinds of rituals with charms still exist, although perhaps not to the same extent as in their country of origin but they may, and very often do, interfere with Western medical approaches.

An example of the type of dilemmas the interpreters faced, which took place during our observations, is the concept of blood. While Spanish doctors consider blood tests to be a key element in diagnosing potential diseases, many foreign sub-Saharan nationals consider taking blood to be a rare witchcraft practice, and thus refuse to undergo blood tests. In all cases the interpreters had stated in their questionnaire responses that they found it essential for them to explain the reasons why these tests had to be carried out and also the difference in conceptualisation. They also stated that practitioners were not aware either, so communication could not take place unless the concepts were further explained to all parties involved and we observed that this was their daily practice.

Another frequent example was the way in which Chinese people show respect by not looking conversation participants straight in the eye. In the questionnaire responses, participants expressed that most practitioners who used CIs were not aware of this and had stated at different times during informal conversations that they thought these patients were rude and impolite because they did not look directly at them. During the observations it was evident that one practitioner was becoming annoyed with the patient and actually asked her 
to look her in the eye. The interpreter then had to explain to the practitioner that for Chinese people this was respectful behaviour.

As commented on in the questionnaire responses, interpreters thought it was important to raise awareness on cultural and ideological differences not only to users but also to health professionals in order to facilitate communication, as they believed that health professionals tend to give scant attention to cultural differences, as opposed to linguistic differences which they are much more aware of. Consequently, this may actually be the source of misunderstandings and miscommunication, as it poses a risk for patients who do not understand instructions and may be misdiagnosed. The interpreters participating in this study did in fact take on this role and acted as information facilitators for both patients and practitioners.

The interpreters believed they were being impartial in all cases according to the questionnaire responses, and their perception was that they strictly followed codes of ethics; however, after analysing their work, they were seen not being as impartial as they believed they were. Aside from the examples given, they assumed functions such as coordinating conversations, omitting 'irrelevant' information, and adding cultural and further explanations.

By observing interpreters in their daily practice, we can reflect on specific contexts which tend to re-occur and which need specific solutions and should therefore be included in future guidelines.

\section{Conclusions}

CIs must communicate messages containing language and culture which makes him/her a bridge between the interlocutors and thus a visible part of the exchange. The interpreter normally finds him/herself explaining and clarifying cultural differences, traditions, ideological concepts, etc. in order to get the message across. Thus a specific code of ethics for CIs could describe the type of clarifications and contexts where information could be added.

As has been seen in our limited sample, interpreters are aware of the need to use a code of ethics; however, this is not a magic wand that will solve their daily conflicts. It is obvious that codes of ethics cannot provide answers for each particular dilemma. In theory, the more systemised standards and procedures are, the more standardised and error-free contexts will become. However, in everyday work each practitioner and user will provide interpreters with new conflicts and decision making processes. Older professionals may have an important role in helping younger interpreters by sharing anecdotes which deal with different ethical issues in a non-judgemental environment, so that 
new interpreters can think about the different situations they may encounter, and thus have realistic expectations.

This study has shown that further work needs to be carried out in establishing a code of ethics for Spanish healthcare CIs taking into account the specific tasks and contexts in which they work. These contexts and situations force them to act as facilitators, providing explanations and further information to both health professionals and patients. With practical and coherent norms an interpreter would have more certainty regarding their behaviour and would be able to discern facilitation (for example adding general information, such as information about the health system and explaining the vaccination schedule or that in the Western culture it is generally accepted that blood tests are carried out by doctors) from interference (adding information that the interpreter is not a specialist in, such as why a certain drug has been prescribed). When emotional and sensitive issues come into play, a standardised practical model can help to stay rational and professional.

All interpreters were knowledgeable of codes of ethics and used a specific code that they were familiar with. When posed with ethical dilemmas, the respondents partially followed the guidelines of a code of ethics. Although they established and articulated values, obligations, responsibilities, and ethical issues of their workplace, their supposed impartiality was sometimes biased in favour of one of the parties (in this study it was always the patient), providing more information beyond what was explicitly mentioned by health practitioners, and adding cultural explanations in order to enable patients to understand why a practitioner was either asking for specific tests or prescribing a medicine. From the observations, we can see that ethical guidelines do come into play when interpreters find themselves under emotional pressure or when they have sensitive issues which involve critical decision making.

Another key issue which arose when analysing the questionnaire responses was the fact that all the interpreters belonged to the host culture and were thus guided by it, and in consequence the interpreter's own, understanding of ethics. It would be extremely interesting to study this parameter in settings where interpreters belong to the original culture or a third culture.

Interpreters are often faced with a dilemma: whether to simplify or to add extra information to their interpreting, and it is difficult to trace the line of partiality risks. Perhaps some useful advice would be for the interpreter to ask a Spanish practitioner to adjust their language register to a level that a non-Spanish speaker may understand, i.e. if communication problems were to arise, then an interpreter should bring this fact to the attention of all the parties. 
Impartiality gives way to equality, yet when one participant in a conversation cannot fully understand the meaning of the other participant, a power loss takes place and communication is broken. CIs definitely bridge this imbalance and can help to reduce the risk of arbitrariness in healthcare encounters, which are one of the most sensitive contexts in which interpersonal relationships can occur.

Given the situation described above, we believe that corrective actions should be taken to increase the awareness of the complexity of the Cl's profile. Informative sessions would be beneficial in order to explain to associations and institutions that the effectiveness of communication in patient-doctor meetings requires a wide range of skills that go beyond simply a command of languages.

In order to reduce the emotional impact and guarantee professionalism and a good service, CIs should follow a code of ethics. Ethical guidelines will help them reach rational decisions and not be influenced by emotions which may disturb their work. Brief guidelines such as confidentiality (respect others' right to privacy), impartiality (not be biased by any of the parties), faithfulness (make sure the message is faithful to the meta discourse and appropriate in the target language and culture) and integrity (be honest with yourself and your capacity to accept new work) should be given. These guidelines can serve as a first step in order to create a more specific Code of Ethics for CIs in Spain. As we have seen, ethical guidelines help interpreters in their daily practice and add effectiveness to bridging communication, however, more specific ones could improve their work.

\section{References}

ANECA. (2004) Final Report on the Project for the Design for the Degree in Translation and Interpreting in Spain. Electronic version: <www.aneca.es/modal_eval/docs/ libroblanco_traduc_borrador.pdf>

ANGELELLI, Claudia. (2004) Medical Interpreting and Cross-cultural Communication. Cambridge: Cambridge University Press.

ANTONIn, Montserrat. (2010) La mediación intercultural en el sistema de salud de Cataluña. Tarragona: Universitat Rovira i Virgili.

AUSIT. (1996) Code of Ethics for Interpreters and Translators. Australian Institute of Interpreters and Translators Incorporated. Electronic version: <http://www. ausit.org/eng/showpage.php3?id=650>

Baixauli, Lluís. (2014) "Los códigos hablan... pero nosotros decidimos. Aportaciones a la práctica de las MILICS desde la deontología professional." In: Grupo CRIT (eds.) 2014. La práctica de la mediación interlingüistica e intercultural en el ámbito sanitario. Granada: Editorial Comares.

CAMBRIDGE, Jan. (2002) "Interlocutor roles and the pressures on interpreters." In: Valero- Garcés, Carmen \& Guzmán Mancho Barés (eds.) 2002. Traducción e 
interpretación en los servicios públicos: nuevas necesidades para nuevas realidades. Community Interpreting and Translating: New Needs for New Realities. Alcalá de Henares: Servicio de publicaciones de la Universidad de Alcalá, pp. 119-130. CAmBridge, Jan. (2003) "Unas ideas sobre la interpretación en los Centros de Salud." In: Valero-Garcés, Carmen (ed.) 2003. Traducción e interpretación en los servicios públicos. Contextualización, actualidad y futuro. Granada: Comares, pp. 51-69.

CORSELlis, Anne. (2005) "Training interpreters to work in the public services." In: Tennent, Martha (ed.) 2005. Training for the New Millennium: Pedagogies for translation and interpreting. Amsterdam \& Philadelphia: John Benjamins, pp. 153-173.

DRAGOJE, Vesna \& Debbie Ellam. (2012) "Shared perceptions of ethics and interpreting in health care." Paper presented at the Fifth Critical Link Conference, Sydney, Australia. Electronic version: <https://staticl.squarespace.com/static/52d566cbe4b0002632d34367/t/5347f7d2e4b0b891fcd56cde/1397225426939/ CL5Ellam_Fowler.pdf>

FRANCO AIXELÁ, Javier. (2010) "Una revisión de la bibliografía sobre traducción e interpretación médica recogida en BITRA (Bibliografía de Interpretación y Traducción)."Panace@ Revista de Medicina, Lenguaje y Traducción 11:32, pp. 151-160.

García-BeyaerT, Sofía \& Jordi Serrano-Pons. (2009) "Recursos para superar las barreras lingüístico-culturales en los servicios de salud." In: Morera Montes, Joaquín; Alberto Alonso Babarro \& Helena Huerga Aramburu (eds.) 2009. Manual de atención al inmigrante. Barcelona: Ergon, pp. 53-66.

GENTILE, Adolfo; Uldis Ozolins \& Mary Vasilakakos. (1996) Liaison Interpreting. A handbook. Victoria: Melbourne University Press.

GILE, Daniel. (1995) Basic concepts and models for interpreter and translator training. Amsterdam \& Philadelphia: John Benjamins.

GIMÉNEZ, Carlos. (2010) El interculturalismo: Propuesta conceptual y aplicaciones prácticas. Zarautz: Itxaropena.

Hale, Sandra. (1997a) "Interpreting Politeness in Court. A Study of Spanish Interpreted Proceedings.” In: Campbell, Stuart \& Sandra Hale (eds.) 1997. Proceedings of the 2nd Annual Macarthur Interpreting and Translation Conference. Research, Training and Practice. Milperra: UWS MAcarthur/LARC, pp. 37-45. HALE, Sandra. (1997b) "The Interpreter on Trial: Pragmatics in Court Interpreting." In: Carr et al. (eds.) 1997. The Critical Link: Interpreters in the Community. Amsterdam \& Philadelphia: John Benjamins, pp. 201-211.

INTERNATIONAL MEDICAL INTERPRETERS ASSOCIATION (IMIA). "Código de ética." Electronic version: <http://www.imiaweb.org/code/SPA.asp>

LLEVOT, Nuria. (2005) "El mediador intercultural: perfiles y profesionalización." I Jornadas de mediación intercultural en Canarias. Electronic version: <http:// www.innovatica.es/index.php/servicios-productos/25-acciones/13-mediaci> 
MASON, Ian. (1999) "Introduction." The Translator 5:5, pp. 147-160.

MikKELSON, Holly. (1996) "Community Interpreting. An Emerging Profession." Interpreting 1:1, pp. 125-129.

MiKKELSON, Holly. (1998) "Towards a Redefinition of the Role of the Court Interpreter." Interpreting: International Journal of Research and Practice in Interpreting 3:1, pp. 125-129.

NATIONAL ACCREDITATION AUTHORITY FOR TRANSLATORS AND INTERPRETERS LTD (NAATI). (2000) Ethics of translation and interpreting: A guide to professional conduct in Australia. Canberra: Instant Colour Press.

NAVAZA, Bárbara; Laura Estévez \& Jordi Serrano. (2009) “«Saque la lengua, por favor». Panorama actual de la interpretación sanitaria en España.” Panace@ Revista de Medicina, Lenguaje y Traducción 10:30, pp. 141-156.

NAVAZA, Bárbara. (2011) “¿Cómo nos comunicamos en hospitales y centros de salud en el siglo XXI?” In: Carmen Valero-Garcés (ed.) 2011. Traducción e Interpretación en los Servicios Públicos en los Siglos XXI: Avanzando hacia la Unidad en Medio de la Globalización. Alcalá de Henares: Servicio de Publicaciones de la Universidad, pp. 75-83.

NAVAZA, Bárbara. (2014) "Interpretación sanitaria y mediación intercultural." In: Gutiérrez Rodilla, Bertha \& Fernando Navarro (eds.) 2014. La importancia del lenguaje en el entorno biosanitario. Barcelona: Fundación Dr. Antonio Esteve.

NSW Health. (2006) "Interpreters - Standard Procedures for Working with Health Care Interpreters." Primary Health and Community Partnerships Branch, NSW Health. Policy Document, PD2006_053. Electronic version: <http://www1. health.nsw.gov.au/pds/ActivePDSDocuments/PD2006_053.pdf >

OzOLINS, Uldis. (2000) "Communication needs and interpreting in multilingual settings: The international spectrum of response." In: Roberts, Roda et al. (eds.) 2000. The Critical Link 2: Interpreters in the Community. Amsterdam \& Philadelphia: John Benjamins, pp. 21-33.

Ozolins, Uldis. (2004) "Factors that determine the provision of Public Service Interpreting: comparative perspectives on government motivation and language service implementation." JoSTrans, Journal of Specialised Translation 14, pp. 194-215.

Ozolins, Uldis. (2014) "Descriptions of Interpreting and other Ethical Consequences." FITISPos International Journal 1.

PenA-DíAz, Carmen; Bruno Echauri Galván \& Mónica Olivares Leyva. (2014) "Las funciones del mediador intercultural en el ámbito sanitario: habilidades y conocimientos." TONOS DIGITAL 26, pp. 1-7.

PHELAN, Mary. (2010) "Interpreting in Northern Ireland." Translation Ireland 18:2, pp. 99-107.

Pöllabauer, Sonja. (2004) "Interpreting in Asylumn Hearings. Issues of role, responsibility and power." Interpreting 6:2, pp. 143-180. 
PONCE MÁRQUEZ, Nuria. (2011) "Interpretación social y mediación intercultural: Juntos pero no revueltos. El caso de Sevilla Acoge." In: Valero Garcés, Carmen (ed.) 2011. Traducción e interpretación en los servicios públicos en un mundo interconectado. Alcalá de Henares: Universidad de Alcalá.

RAGA, Francisco. (2008) Mediaciones interculturales. Valencia: Universitat de València, Centro de Estudios sobre Comunicación Interlingüística e Intercultural. Lynx.

Rudvin, Mette. (2007) "Professionalism and ethics in community interpreting: The impact of individualism versus collective group identity." Interpreting 9:1, pp. 47-69.

SALES, Dora. (2005) "Panorama de la medicación intercultural y la traducción/ interpretación en los servicios públicos en España.” Translation Journal 9:1.

SALES, Dora \& Carmen Valero. (2006) "Bibliografía sobre traducción e interpretación en los servicios públicos y mediación intercultural." Revista Española de lingüística aplicada, vol. Extra 1. Retos del Siglo XXI en comunicación intercultural: Nuevo mapa lingüístico y cultural de España, pp. 249-285.

Solow, Sharon. (1980) Sign Language Interpreting: A Basic Resource. Silver Spring, MD: National Association of the Deaf.

TATE, Granville \& Graham Turner. (2001) "The Code and the Culture of Sign Language Interpreting- in search of the new breed's ethics." In: Harrington, Frank \& Graham Turner (eds.) 2001. Interpreting interpreting: Studies and reflections on sign language interpreting. Gloucertershire: Douglas Mclean, pp. 56-66.

VALERO-GARCÉS, Carmen. (2006) Formas de mediación intercultural e interpretación en los servicios públicos. Conceptos, datos, situaciones y práctica. Granada: Comares.

VAlero-GARCÉs, Carmen \& Anne Martin. (2008) Crossing Borders in Community Interpreting. Definitions and Dilemmas. Amsterdam \& Philadelphia: John Benjamins.

VARGAS-URPI, Mireia. (2014) "ISP y/o mediación intercultural: la realidad de los profesionales que trabajan en el contexto catalán." Cuadernos de ALDEEU 25, pp. 131-164.

WADENSJÖ, Cecilia. (2011) "Interpreting in theory and practice: Reflections about an alleged gap." In: Alvstad, Cecilia; Adelina Hild \& Elisabet Tiselius (eds.) 2011. Methods and Strategies of Process Research. Integrative Approaches in Translation Studies. Amsterdam \& Philadelphia: John Benjamins, pp.13-21.

WADENSJÖ, Cecilia. (1998) Interpreting as Interaction. Harlow: Addison Wesley Longman Limited. 


\section{BIONOTA / BIONOTE}

Carmen Pena Díaz es profesora de traducción en el Departamento de Filología Moderna de la Universidad de Alcalá (Madrid, España). Ha impartido clases en la Universidad de Vigo (España) y en Louisiana State University (EE. UU.). Sus áreas de investigación son bilingüismo, traducción y ESP. Es miembro del grupo de investigación FILWIT que investiga nuevas tecnologías en la enseñanza de idiomas y traducción, líder de un grupo de investigación acreditado a nivel nacional InterMed y coordina la sección inglés-español del Máster de Comunicación Intercultural, Traducción e Interpretación en los Servicios Públicos de la Universidad de Alcalá.

Carmen Pena-Díaz is a translation lecturer at the Department of Modern Philology at Alcalá de Henares University (Madrid, Spain). She has previously taught at Vigo University (Spain) and at Louisiana State University (USA). Her research areas are bilingualism, translation and ESP. She is member of the FILWIT research group which researches new technologies in language and translation teaching, leader of a nationally accredited research group InterMed and coordinates the English-Spanish section of the European Public Service Intercultural Communication, Translating and Interpreting Master's Degree at Alcalá University. 
